\title{
Simulation and experimental study on the air jet pulverization of TiC-containing slag
}

\author{
Dongsheng Wang ${ }^{1,2, *}$, Jianbo Zhang ${ }^{1,2}$, Qinge Zhao ${ }^{2}$, and Jiaxu Huang ${ }^{1}$ \\ ${ }^{1}$ Pangang group research institute Co. Ltd., Panzhihua 617000, China \\ ${ }^{2}$ State key laboratory of V and Ti resources comprehensive utilization, Panzhihua 617000, China
}

\begin{abstract}
Process of "high temperature carbonization and low temperature chlorination", which was considered to be one of the most promising technologies, could extracte more than $70 \%$ titanium from the furnace slag containing $\mathrm{TiO}_{2} 10 \%-30 \%$. TiC-containing slag was the product of high temperature carbonization, and to meet the requirement of the following chlorination process, it needs to be crushed and grounded to a suitable size distribution. The air jet pulverization of TiC-containing slag was studied in this paper. On the one hand, By CFD numerical simulation, the distribution regularity of nozzle flow field about the main crushing equipment was obtained with different throat diameters and crushing gas pressures. On the other hand, the influences of nozzle throat diameter, crushing pressure, and collision angles on the particle size of the powder were studied by experiment. With the better parameters, the particle size distribution of the product powder was uniform.
\end{abstract}

\section{Introduction}

Vanadium-titanium magnetite is a kind of complex ore, which contains many valuable elements, such as Fe, Ti and V. The found reserve is nearly 48 billion tons in the world, and it is mainly distributed in Russia, South Africa, China and New Zealand. In China, it is mainly located in Sichuan, Hebei and Anhui provinces. In the present utilization way of the vanadium-titanium magnetite, the raw ore is first dealed with a mineral separation process to obtain the iron concentrate, and the obtained tailing is further beneficiated to obtain the ilmenite concentrate. In the ilmenite concentrate, titanium dioxide is concentrated $45 \%-55 \%$ furthermore, the ilmenite is smelted by electric furnace, after which the ilmenite is reduced to iron and the slag contained titanium dioxide $70 \%-85 \%$. The slag is treated by the chlorination process of molten salt to produce $\mathrm{TiCl}_{4}$, which is raw material of titanium dioxide or sponge titanium. In the iron concentrate, the $\mathrm{Fe}_{2} \mathrm{O}_{3}$ is gathered to $50 \%-60 \%$, and by blast furnace smelting, $\mathrm{Fe}_{2} \mathrm{O}_{3}$ is reduced to iron, at the same time, other materials form blast furnace slag contained $\mathrm{TiO}_{2} 10 \%-30 \%$ [1]. At present, this kind of slag is regarded as industrial wastes, and leads to great loss of titanium resources. In recent years, many scholars do lots of work to recovery titanium from this kind of blast furnace slag, such as "making silicon alloy"[2], "enrichment of perovskite and dressing" [3], "separation of titanium carbide after carbon thermal reduction " [4], " acid leaching extraction" [5],

*Corresponding author: 15881250692@163.com 
"high-temperature carbonization and low-temperature chlorination" [6] and so on. By high temperature carbonization and low temperature chlorination process, the titanium could recover more than $70 \%$ from $\mathrm{BF}$ slag, therefore, it is considered to be one of the most possible methods for industrialization. The basic principle of process is that $\mathrm{TiO}_{2}$ is reduced to $\mathrm{TiC}$ by reacting with coke. By this reaction, the $\mathrm{BF}$ slag is transformed to slag contained TiC. And the TiC-containing slag could be further reacted with $\mathrm{Cl}_{2}$ at a low temperature to produce $\mathrm{TiCl}_{4}$. Faninaly, the $\mathrm{TiCl}_{4}$ is used to produce $\mathrm{TiO}_{2}$. In order to promote the reaction between the TiC-containing slag and $\mathrm{Cl}_{2}$, the TiC-containing slag needs to be crushed and grinded to a certain size range. The mass percentage of less than $32 \mu \mathrm{m}$ is asked to be less than $20 \%$ and the mass percentage of $32 \mu \mathrm{m}-150 \mu \mathrm{m}$ is required more than $75 \%$. By traditional ball mill process, the percentage of $32 \mu \mathrm{m}-150 \mu \mathrm{m}$ accounted for only $35 \%$. it is far satisfying the raw material demands for low-temperature chlorination. So it is necessary to search new method to fabricate TiC-containing slag powder.

The principle of air jet pulverization is like this: materials are accelerated to a certain speed by high-speed airflow. Then it is crushed, sheared and pulverized by collision between particles and partials or particles and target. Compared with the existing crushing technology, the main merits of air jet pulverization are avoid excessive grinding and the products have a narrow particle size distribution [7]. Airflow crushing equipment is usually divided into 5 types: flat airflow grinding, circulating pipe airflow grinding, jet airflow grinding, target airflow grinding and fluidized bed airflow grinding $[8,9]$. In this paper, grinding of TiC-containing slag is studied by simulation and experiments. By CFD numerical simulation, the distributed regularity of nozzle flow field is obtained with different throat diameters and gas pressures. Then by experimental study, the effect of process parameters, such as nozzle throat diameter, crushing air pressure and collision angle on the particle size distribution are researched, coupled with rate of product and yield.

\section{Materials and methods}

\subsection{Experimental materials}

The water quenched TiC-containing slag was used as experimental feed. The ingredients are as follows: $\mathrm{CaO} 27.4 \%, \mathrm{SiO}_{2} 24.69 \%$, $\mathrm{TiC} 14.14 \%, \mathrm{Al}_{2} \mathrm{O}_{3} 13.25 \%, \mathrm{MgO} 8.16 \%, \mathrm{Ti}_{2} \mathrm{O}_{3}$ $4.46 \%$, C $2.98 \%$, Fe $1.41 \%$ and Other $3.51 \%$. The density of water quenching slag is $0.95 \mathrm{t} / \mathrm{m}^{3}$, and the particle size distribution is shown in table 1 .

Table 1. The size distribution of water quenched slag.

\begin{tabular}{|c|c|c|c|c|c|}
\hline Particle size $(\mu \mathrm{m})$ & $<32$ & $32-150$ & $150-833$ & $833-1397$ & $1397-3000$ \\
\hline Mass fraction $(\%)$ & 1.35 & 6.79 & 36.41 & 33.32 & 22.13 \\
\hline
\end{tabular}

\subsection{Experimental methods}

Numerical simulation and experiments were used to study the effect of air jet crushing. The nozzle structure, which is the core component of machine, was analyzed by software of Ansys Fluent 15. For nozzle throat diameter $42 \mathrm{~mm}$ and $60 \mathrm{~mm}$, the nozzle flow field and the exit airflow velocity were calculated carefully under different crushing gas pressure 2 $\mathrm{kPa}, 5 \mathrm{kPa}, 10 \mathrm{kPa}, 20 \mathrm{kPa}$ and $60 \mathrm{kPa}$. The 3D model and meshing of pulverized cavity were established as figure 1 and figure 2, respectively. For simulation, a steady state flow model was established. The air was treated as an ideal gas and without considering the influences of the filter wall on the flow field. The airflow field adopted SIMPLE coupling algorithm of pressure and velocity and standard k- $\varepsilon$ equation model, followed by the 
conservation laws of mass, momentum and energy. The governing equations were continuity equation, momentum equation, $\mathrm{k}$ turbulent kinetic energy equation and $\varepsilon$ dissipation rate equation.

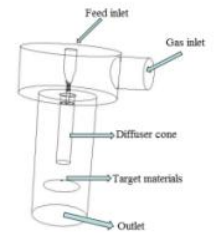

Fig. 1. 3D model of pulverized cavity.

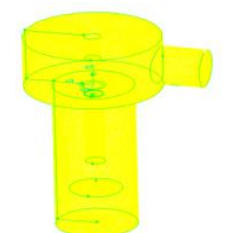

Fig. 2. Meshing by Gambit.

Combined with the characteristics of raw material and the requirements of product size, the airflow grinding machine was selected as the main equipment. Figure 3 shows the experiment flow of air jet pulverization of TiC-containing slag. The particle size distribution of finished slag was analyzed by laboratory standard sieve, and the percentage of less than $32 \mu \mathrm{m}$ was measured by wet sieving, which refer to the Chinese national standard GB/T 1345-2005.

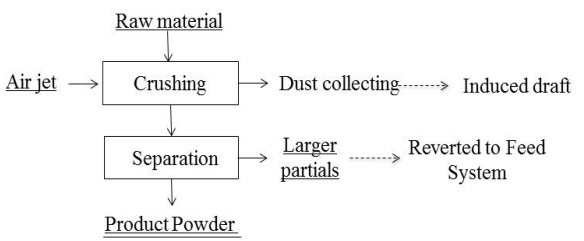

Fig. 3. Flow chart of air jet pulverization process.

\section{Results and discussion}

\subsection{Simulation results analysis}

Figure 4 shows the Diagram of simulation results about airflow velocity for nozzle throat dimeter $42 \mathrm{~mm}$ and $60 \mathrm{~mm}$ under the crushing air pressure $10 \mathrm{kPa}$. From the figure 4 , it is found that the airflow velocity in the center is about $18 \mathrm{~m} / \mathrm{s}$ smaller than that at the circumference under the condition of nozzle throat diameter $42 \mathrm{~mm}$. These results suggested that the airflow velocity isn't very uniform. In contrast, with nozzle throat diameter $60 \mathrm{~mm}$, it seems no big difference between the center and the circumference. Therefore, the materials could be accelerated accordantly. Considering the matching between the air jet flow tube and the nozzle, the nozzle throat diameter $60 \mathrm{~mm}$ seems better.

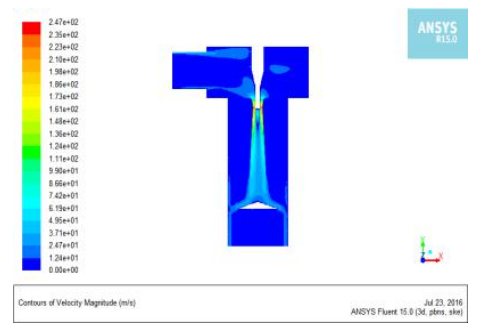

(a)

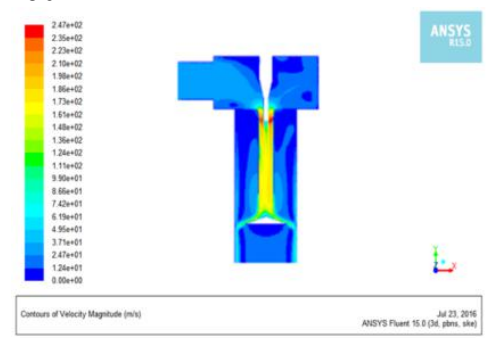

(b)

Fig. 4. Diagram of simulation results about airflow velocity with the crushing air pressure $10 \mathrm{kPa}$ (throat diameter: a- $42 \mathrm{~mm}, \mathrm{~b}-60 \mathrm{~mm}$ ).

The changes of gas mass flow rate with different crushing air pressures are shown in Figure 5. For the same throat diameter, the higher the crushing air pressure, the greater the mass flow. For the same air pressure, the greater the throat diameter, the greater the mass 
flow rate. Figure 6 shows the change of throat airflow velocity with different crushing pressures. For the same nozzle throat diameter, with the increase of crushing gas pressure, the outlet airflow speed increases, as well as the crushing strength. When the crushing gas pressure increases from $2 \mathrm{kPa}$ to $60 \mathrm{kPa}$, the airflow velocity of nozzle throat diameter $42 \mathrm{~mm}$ increases from $150 \mathrm{~m} / \mathrm{s}$ to $380 \mathrm{~m} / \mathrm{s}$, and the airflow velocity of nozzle throat diameter $60 \mathrm{~mm}$ increases from $98 \mathrm{~m} / \mathrm{s}$ to $262 \mathrm{~m} / \mathrm{s}$. For the same pulverized gas pressure, the greater throat diameter, the lower airflow velocity. The airflow speed of the throat diameter $60 \mathrm{~mm}$ is almost half of the number of throat diameter $42 \mathrm{~mm}$.

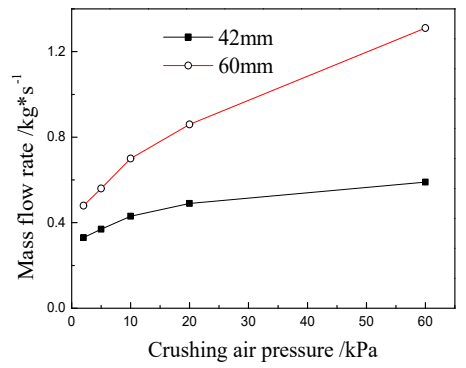

Fig. 5. The change of gas mass flow with different crushing pressures.

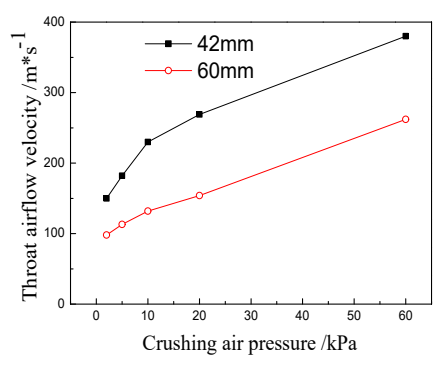

Fig. 6. The change of throat airflow velocity with different crushing pressures.

\subsection{Different throat diameters}

The particle size distribution with different nozzle throat diameters is shown in figure 7 . From the figure 7(a), as the nozzle throat diameter increases from $42 \mathrm{~mm}$ to $60 \mathrm{~mm}$, the mass proportion of less than $32 \mu \mathrm{m}$ increases from $15.6 \%$ to $17.6 \%$, as well as the proportion of $32 \mu \mathrm{m}-150 \mu \mathrm{m}$ adds from $78 \%$ to $81.3 \%$. And there is a huge decline of particle size greater than $150 \mu \mathrm{m}$, which falls from $6.4 \%$ to $1.1 \%$. The experimental data is consistent with the simulation results. According to the simulation results, For the throat diameter $60 \mathrm{~mm}$ and crushing gas pressure $10 \mathrm{kPa}$, the mass flow rate was $0.7 \mathrm{~kg} / \mathrm{s}$, which was $0.38 \mathrm{~kg} / \mathrm{s}$ greater than that of the nozzle throat diameter $42 \mathrm{~mm}$. And the throat velocity was $132 \mathrm{~m} / \mathrm{s}$, which was $98 \mathrm{~m} / \mathrm{s}$ lower than that of the throat diameter $42 \mathrm{~mm}$. In addition, it can be seen from figure 7 (b) that with nozzle throat diameter $60 \mathrm{~mm}$ the mass ratio of product and feed increases about $10 \%$ and the output increases about $50 \%$, respectively. Both of them are relatively higher than the numbers with nozzle throat diameter $42 \mathrm{~mm}$.

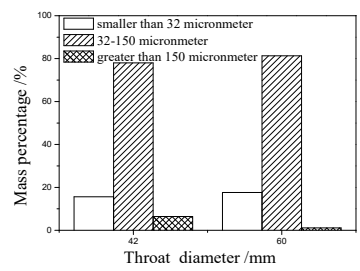

(a)

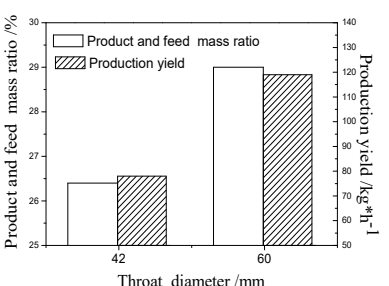

(b)

Fig. 7. The changes of particle size, product rate and yield with different throat diameters.

\subsection{Different crushing air pressures}

The crushing pressure refers to the surface pressure of dry air entering the inlet of the subsonic nozzle after oil and water removed [10]. Figure 8 shows the influences of different pressures on the particle size, yield and output with throat diameter $42 \mathrm{~mm}$. It can be seen 
from Figure $8(\mathrm{a})$, with the gas pressure decreases from $60 \mathrm{kPa}$ to $10 \mathrm{kPa}$, the particle size proportion of $32 \mu \mathrm{m}-150 \mu \mathrm{m}$ increases from $70.8 \%$ to $78 \%$, and the proportion of less than $32 \mu \mathrm{m}$ decreases from $28.6 \%$ to $15.6 \%$. Under the gas pressure of $10 \mathrm{kPa}$, the mass percentage of particle size $32 \mu \mathrm{m}-150 \mu \mathrm{m}$ is the largest and accounts for $78 \%$. As the reduction of crushing pressure, the throat airflow velocity seems to slow within a certain range. According to the results of simulation calculations, along with the crushing gas pressure reduced from $60 \mathrm{kPa}$ to $10 \mathrm{kPa}$, the airflow speed reduced from $380 \mathrm{~m} / \mathrm{s}$ to 230 $\mathrm{m} / \mathrm{s}$ at nozzle exit. As the material speed slowing, the collision energy decreases. The figure 8 (b) is the changes of product rate and yield. Along with the crushing gas pressure reducing, the product rate and yield turn to be lower and lower. The mass ratio of product and feed reduces from $37 \%$ to $26.4 \%$, and the yield declines from $106 \mathrm{~kg} / \mathrm{h}$ to $78 \mathrm{~kg} / \mathrm{h}$, respectively. By calculation, the crushing capacity under the condition of gas pressure $10 \mathrm{kPa}$ accounts for $60 \%$ of that under the condition of gas pressure $60 \mathrm{kPa}$.

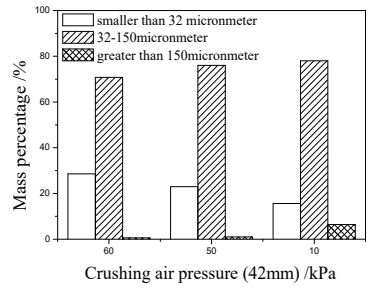

(a)

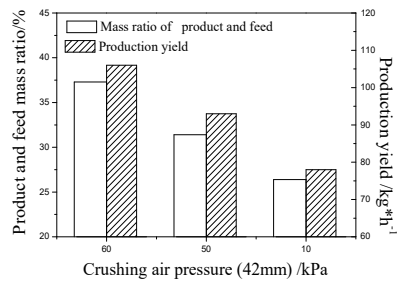

(b)

Fig. 8. The changes of particle size, product rate and yield with different crushing air pressures.

\subsection{Different collision angles}

Under the condition of nozzle throat diameter $60 \mathrm{~mm}$ and crushing pressure $10 \mathrm{kPa}$, the impacts of collision Angle is shown in figure 9.

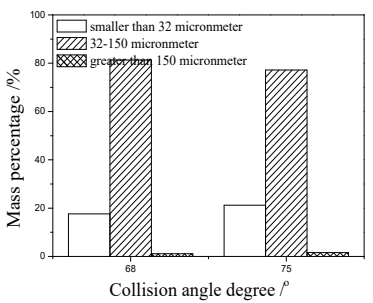

(a)

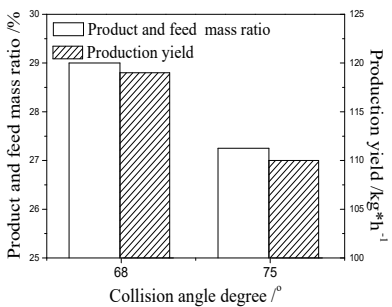

(b)

Fig. 9. The changes of particle size, product rate and yield with different collision angles.

It can be seen from the figure 9(a) with the collision angle increases from $68^{\circ}$ to $75^{\circ}$, The particle size of finished slag is obviously finer, and the mass percentage of particle size less than $32 \mu \mathrm{m}$ increases from $17.6 \%$ to $21.2 \%$ significantly. Figure $9(\mathrm{~b})$ shows that product rate and yield slightly decrease as the collision angle increasing. The mass ratio of product and feed decreases $1.7 \%$, and the yield decreases $9 \mathrm{~kg} / \mathrm{h}$, respectively. The particle size distribution, product rate and yield are influenced by the shape of the target material. In general, the top Angle of the target material is defined as the target material's angle, and it is usually inelastic and non-vertical collision in the crushing process, in which the part of lost energy is used to break particles. The larger target material's angle, the greater energy loss, and the greater the energy of crushing particles.

\subsection{Product size distribution and energy consumption}


Under the condition of better process parameters, crushing gas pressure $10 \mathrm{kPa}$, throat diameter $60 \mathrm{~mm}$, and collision Angle $68^{\circ}$, the stability of product granularity and equipment energy consumption were evaluated by test which continuous 4 hours. The particles size distribution in products is shown in table 2 . The mass proportion of particle sizes less than $32 \mu \mathrm{m}, 32 \sim 150 \mu \mathrm{m}$ and greater than $150 \mu \mathrm{m}$ was $18.97 \%, 77.77 \%$, and $3.26 \%$, respectively. And the energy consumption in the test was $70.2 \mathrm{kWh} / \mathrm{t}$.

Table 2. The particles size distribution in products.

\begin{tabular}{|c|c|c|c|}
\hline Sample & $<32 \mu \mathrm{m}(\%)$ & $32 \sim 150 \mu \mathrm{m}(\%)$ & $>150 \mu \mathrm{m}(\%)$ \\
\hline Average & 18.97 & 77.77 & 3.26 \\
\hline
\end{tabular}

\section{Conclusion}

1. The data of mass flow rate and airflow velocity under different throat diameters and crushing pressures have been calculated. Compared with nozzle throat diameter $42 \mathrm{~mm}$, the nozzle throat diameter $60 \mathrm{~mm}$ was probable better, and the accelerated characteristic of the materials were more uniform.

2. Nozzle throat diameter and crushing gas pressure were two key factors influencing the particle size distribution and the output. Increasing the nozzle throat diameter or decreasing crushing gas pressure could reduce the airflow velocity with the crushing efficiency reduced.

3. The better process parameters of air jet pulverization of TiC-containing slag were obtained: the nozzle throat diameter $60 \mathrm{~mm}$, gas pressure $10 \mathrm{kPa}$, and collision Angle $68^{\circ}$. With the better parameters, The average particle size distribution of TiC-containing slag was as follows: less than $32 \mu \mathrm{m} 18.97 \%$, 32 $\sim 150 \mu \mathrm{m} 77.77 \%$ and greater than $150 \mu \mathrm{m} 3.26 \%$.

\section{References}

1. Liu S and Yang S 2007 J. Light Metal 7 48-50

2. Li Z, Liu T and Li Z 1996 J. Chongqing Univ. 19 82-86

3. Sui Z, Guo Z and Zhang Li 2006 J. Mater. and Metall.5 93-97

4. Feng C and Zhang J 1997 J. Miner. Utiliz. 634

5. Liu X and Sui Z 2002 J. Chin. Nonferrous Met. 121281

6. Huang S, Pan J and Zhang R 1994 Iron Steel V. Ti. 1517

7. Chen H 2007 PHD dissertation (Sichuan: Sichuan university) p 1

8. Yang Z 1988 SuperfineJet Pulverization (Beijing: chemical industry press) p 263

9. Li F 2000 Ultrafine Powder Technology (Beijing: national defense industry press) p 83

10. Zhou X, Chen H and Lu C 2011 Powder metall. Technol. 29 46-49 